\title{
Responses and Thoughts of Transportation Construction Projects in the Reform of Environmental Review and Approval System in the New Situation
}

\author{
Haibo Yao ${ }^{1,2}$, Bing Yao ${ }^{1,2}$, Shihong $\mathrm{Wu}^{1, *}$, Jian $\operatorname{Han}^{1,2}$ \\ ${ }^{1}$ Tianjin Research Institute for Water Transport Engineering, Tianjin, 300456, China \\ ${ }^{2}$ Environmental Technology Development of TIWTE (Tian Jin), Tianjin, 300456, China
}

\begin{abstract}
The Ministry of Ecology and Environment has promoted the reform of the environmental impact assessment approval system for construction projects. It has formulated and implemented a positive list of environmental assessment approvals, simplified and optimized the environmental assessment approval process, improved approval efficiency, and effectively guaranteed the smooth development of various construction projects. The long-term implementation mechanism in the future points out the direction; through the study of the reform of the environmental review and approval system under the new situation, the corresponding suggestions for the construction unit and technical unit of the transportation construction project are put forward
\end{abstract}

\section{Foreword}

At present, China's social economy is gradually developing from extensive to refined. With the improvement of economic level, people pay more attention to environmental protection. Green economy and low-carbon economy are the obvious characteristics and products of the current era. The environmental impact assessment system is the source of the prevention of environmental pollution and ecological protection in China's environmental protection management. Its principle of "protection first" [1-2] helps to resolve the tension and conflict between environmental protection and economic development, and is very important for implementation. The sustainable development strategy is of great significance to promote the coordinated development of economy, society and environment [3-4]. The transportation industry is an important industry related to the national economy and people's livelihood, and it is the core of the country's infrastructure construction. As an important industry classification for environmental impact assessment, the transportation industry has cumbersome procedures, low efficiency, and "emphasis on approvals and oversight" in its approval. [57], not only failed to play the role of environmental impact assessment, but also increased the burden on the transportation authorities, making the implementation of the environmental protection "three simultaneous" measures in the implementation of transportation construction projects lack of supervision [8-10], so Environmental impact assessment of transportation construction projects is a mere formality.

\section{Existing problems in environmental impact assessment of construction projects and reform of examination and approval system}

China's environmental impact assessment system started late. As a prerequisite for construction projects, it has problems with insufficient capacity building in terms of specific system construction, talent reserves, and functional organization settings. The relevant laws and regulations are still incomplete, and punishment enforcement methods are relatively incomplete. single. In order to implement the deployment requirements of the Party Central Committee and the State Council on deepening the reform of "delegating management and service" and optimizing the business environment, promote the transformation of government functions to reduce approvals, strengthen supervision, and provide better services, stimulate economic vitality, and reduce the burden on enterprises, the General Office of the State Council The notice requires 16 cities, including Beijing, Tianjin, Chongqing, and Xiamen, to carry out pilot reforms in the whole process of engineering construction project approval [11-12], continue to promote streamlined administration, decentralization, decentralization, combination of decentralization, optimization of services, and continuous improvement of the government efficacy. Since the 18th National Congress of the Communist Party of China, the Ministry of Ecology and Environment has adopted the "Overall Plan for the Reform of Ecological Civilization System" as its guiding principle [13-15], and adopted the reform of environmental assessment and 
approval as an important measure to promote the reform of administrative approval [16-18]. The "Regulations on Environmental Protection Management of Construction Projects" also further implement the requirements of the reform work of "delegating management, delegating management and serving". Local ecological and environmental administrative approval authorities have gradually promoted the approval reform of the "notice and commitment system" for environmental impact assessment according to industry classifications for construction projects with "controllable environmental impact, low risk, relatively clear management measures, and compliance with the planning and environmental assessment" according to requirements.

Under the current situation of the new crown epidemic, the national ecological environment system has adopted new forms such as "no-face approval" and "notification and commitment system approval" to ensure that enterprises resume work and production. The Ministry of Ecology and Environment, in accordance with the "Construction Project Environmental Impact Assessment Classification Management List", has decided to implement pollution discharge permit registration management related to the people's livelihood and included in the "Fixed Pollution Source Pollution Permit Classification Management List", social undertakings and service industries, not involving toxic, harmful and Projects in 10 categories and 30 sub-sectors such as the storage of dangerous goods, logistics and distribution are subject to environmental impact assessment exemption management; for engineering construction, social undertakings and service industries, manufacturing, animal husbandry, transportation and other fields, a total of " The 17 categories and 44 sub-sectors in the Directory have expanded the implementation of the EIA notification and commitment system for approval reforms. According to the new crown epidemic situation, the time limit for implementation of the reform is appropriately extended. Effective and widely recognized measures can be solidified to form a long-term mechanism [13], which points out the direction for the long-term implementation mechanism of the current and future construction project environmental review and approval system reforms.

\section{Interpretation of EIA Notification and Commitment System Approval}

The "information" in the "information and commitment system" refers to the administrative agency with the function of examination and approval, which informs the applicant (construction unit) in writing of the standards, conditions, and requirements specified in laws, regulations, rules and related technical specifications behavior. "Commitment" refers to the true intention expressed by the applicant to the examination and approval authority that the matters notified to the administrative authority have been known and understood, and that they are guaranteed to be fulfilled in accordance with the conditions, standards and requirements stipulated by laws, regulations, rules and relevant technical specifications.
The applicant submits the application materials for the approval of construction project environmental impact assessment documents to the administrative examination and approval agency, and has known and understood the matters notified by the administrative agency, and is responsible for the quality of the application materials and the legality, authenticity, accuracy, etc. of related data. The environmental impact assessment conclusion is responsible. There are no environmental violations such as "construction before approval", and will strictly abide by relevant environmental protection laws and regulations, consciously perform environmental protection obligations, and assume the main responsibility of environmental protection. The administrative approval authority directly issues EIA approval documents for construction projects that meet the scope of the commitment system, complete application materials, and conform to the legal form.

\section{The transformation of the supervision method of the ecological environment department}

The reform of the notification and commitment system for the approval of the environmental impact assessment of construction projects has simplified the procedures for the approval of the environmental assessment and is conducive to improving the efficiency of the approval of the environmental assessment documents. However, the resulting quality problems of the environmental assessment documents and the subsequent implementation of the "three simultaneous" system for environmental protection have become An important difficulty in the supervision of the ecological environment department during and after the fact. In order to ensure that the quality of the environmental impact assessment documents of construction projects approved by the implementation of the "notification and commitment system" is not reduced, the ecological environment department will promptly include the approved construction projects into the scope of the "double random and one open" inspection by the environmental administrative law enforcement department, and inform the implementation of the commitment Intensify random inspections of the environmental impact assessment documents of the system; intensify the supervision and inspection of the environmental protection "three simultaneous" of construction projects and the operation process. If the inspection is found to be inconsistent with the notification and commitment system or the environmental impact assessment document has major quality problems, the approval decision shall be revoked according to law, and all the legal consequences and economic losses caused shall be borne by the applicant and the construction unit, and the relevant information shall be incorporated into the credit information platform. Record the situation in the applicant's integrity file; if the construction project has started, it will be punished as "build before approval", and the applicant will no longer apply the EIA approval notification and commitment system, and seriously investigate and deal with the 
implementation of the notification commitment system in the EIA document Violation of laws and regulations.

\section{The response and thinking of the competent department of transportation industry to the reform of environmental review and approval system}

In accordance with relevant requirements such as the "Guiding Opinions on Coordinating the Prevention and Control of the Epidemic and Economic and Social Development of Eco-Environmental Protection," the ecological and environmental administrative department has implemented "exempt management" and "notification and commitment system" approvals for the environmental assessment of some transportation construction projects. It greatly simplifies the relevant approval procedures for environmental assessment documents of transportation construction projects, improves the efficiency of examination and approval, and effectively guarantees the smooth implementation of infrastructure transportation construction projects. After the preliminary trials and the successive introduction of relevant policies, under the new situation, the reform of the EIA notification commitment system for some transportation construction projects will be gradually promoted to form a long-term mechanism for the ecological environment administrative approval agency.

For transportation construction projects approved by the EIA notification commitment system in the relevant procedures, the quality requirements for the preparation of EIA documents in the EIA approval application materials and the strict compliance with relevant environmental protection laws and regulations for the transportation authorities, fulfill environmental protection obligations, assume the main responsibility of environmental protection, and implement " The requirements of the "three simultaneous" system have not been relaxed. Supervision and inspection during and after the administrative examination and approval of the ecological environment makes the environmental assessment of transportation construction projects not just a mere formality, but must be implemented in the entire implementation process of transportation construction projects. The competent department of transportation shall be responsible for the contents and conclusions of the environmental impact report (form) of the transportation construction project submitted by it [19]. The relevant penalties have long been strengthened in legal form.

The reform of the EIA notification and commitment approval system for construction projects further emphasizes the main responsibility of the transportation department for environmental protection. However, the implementation of the system is not conducive to the implementation of the transportation department in the approval process due to the reduction of the technical inspection process such as expert review meetings. The environmental protection measures are checked for deficiencies, and the quality of the environmental assessment documents is less guarantee for the construction unit, which invisibly increases the liability risk of the transportation authority. Therefore, as the main person responsible for the environmental protection work of transportation construction projects, the transportation department should pay full attention to the quality control of environmental impact assessment documents. When conducting environmental assessment commissions, it should give priority to selecting good credit and conforming to the "Guidelines for the Compilation of Construction Project Environmental Impact Reports (Forms) Capacity Building" The (trial) technical unit prepares an environmental impact report (table) for it; the integrity of the technical unit, the number of full-time professional and technical personnel, work performance, scientific research workload, and the number of professional software and equipment equipped are all acceptable. As an important quantitative reference index for the transportation department to compare and select technical units [20]. In addition, the transportation authority should strictly implement environmental protection investment and funding sources during the implementation of transportation construction projects to ensure the strict implementation of the "three simultaneous" system for environmental protection in transportation construction projects.

\section{Conclusion}

Under the new situation, it is imperative to reform the environmental impact assessment examination and approval system for construction projects in the transportation industry. The competent department of transportation must adjust to meet the requirements of the administrative examination and approval department of the ecological environment. Strictly attach importance to and strengthen the whole process management of the environmental impact assessment of transportation construction projects, strictly control the quality of environmental assessment documents of transportation construction projects, strictly abide by environmental protection laws and regulations, consciously perform environmental protection obligations, and assume the main responsibility of environmental protection.

\section{Acknowledgments}

This work was supported by the central level, scientific research institutes for basic R\&D special foundation (Grants Nos. KJFZJJ190205).

\section{References}

1. Tang Shaojun, Jiang Yunfei. On the legal establishment of the "protection priority" principle and the reform of the environmental impact assessment system $[\mathrm{J} / \mathrm{OL}]$. Journal of Dalian University of Technology (Social Science Edition), 2020 (01) [2021-01-06] .

2. Liu Ruoli. On the implementation of the priority principle of environmental protection [D]. 
Southwest University of Political Science and Law, 2019.

3. Liang Hui, Teng Zhikun. Research on the status quo of China's environmental impact assessment and countermeasures[J]. Environmental Science and Management, 2018, 43(09): 6-8+40.

4. Chen Haibin, Li Jichun. Discussion on the development of environmental impact assessment under the new situation [J]. Environmental Science and Management, 2015, 40(10): 192-194.

5. Wang Yizhao, Xu Naizhong, Zhang Yuhuan, Teng Jianbiao. Analysis of the reform and supervision of environmental impact assessment mechanism under the background of simplifying administration and delegating power: Taking Zhuhai City as an example [J]. Environmental Science and Management, 2018, 43(02): 190-194.

6. $\mathrm{Xu}$ Jun, Zhang Min, $\mathrm{Wu}$ Biao. Analyzing the countermeasures and suggestions to deepen the reform of environmental impact assessment [J]. Environmental Impact Assessment, 2019, 41(04): 25-27+45.

7. Musaida Mercy Manyuchi, Charles Mbohwa, Edison Muzenda, Nita Sukdeo. Environmental Impact Assessments and Mitigation[M].CRC Press:202011-26.

8. Office of the State Council, Notice of the General Office of the State Council on the Pilot Reform of the Construction Project Approval System (EB/OL), Guobanfa [2018] No. 33.

9. $\mathrm{Xu}$ Wanxin. On the problems and improvement of my country's environmental protection "three simultaneous" system [D]. Zhejiang Gongshang University, 2019.

10. Lou Xiaojie. Analysis of the problems and countermeasures in the acceptance of environmental protection "three simultaneous"[J]. Energy and Environment, 2019(01):107+113.

11. Ministry of Ecology and Environment "Guiding Opinions on Coordinating the Prevention and Control of Epidemics and Ecological and Environmental Protection of Economic and Social Development" (EB/OL), Huan Zong [2020] No. 13.

12. Zhu Yuan, Yuan Yanting, Yao Rong. Local experience and reform suggestions of "delegating management and service" in environmental impact assessment of construction projects[J]. Environmental Protection, 2019, 47(22): 21-25.

13. Dong Zhanfeng, Li Hongxiang, Ge Chazhong, Wang Jinnan. Macroscopic thinking and framework analysis of ecological civilization system reform[J]. Environmental Protection, 2015, 43(19): 15-19.

14. Wu Xiaoyan. The construction of ecological civilization system in the new era: progress, problems and multi-dimensional paths[J]. Journal of Beijing Jiaotong University (Social Science Edition), 2020, 19(04): 23-28.
15. Zhang Yuxuan. Research on the reform direction of ecological civilization system and economic and social development under the background of "five in one" [J]. Trade Fair Economy, 2020(09): 114-116.

16. Liu Yuqi. Analysis of Environmental Review Approval and Supervision in the Context of "Decentralization, Administration, and Service" Reform: Taking Gui'an New District as an example [J]. Environment and Development, 2019, 31(01): 200-201.

17. Wang Yizhao, Xu Naizhong, Zhang Yuhuan, Teng Jianbiao. Analysis of environmental impact assessment mechanism reform and supervision under the background of streamlining administration and delegating powers: Taking Zhuhai City as an example [J]. Environmental Science and Management, 2018, 43(02): 190-194.

18. Jiang Xiaoqiong. Research on the Supporting System of Environmental Review and Approval under the Background of Streamlining Administration and Decentralization in Shanghai [D]. Shanghai Normal University, 2017.

19. "Environmental Impact Assessment Law of the People's Republic of China", Presidential Order of the People's Republic of China (No. 48).

20. Ministry of Ecology and Environment "Measures for the Supervision and Administration of the Preparation of Environmental Impact Reports (Forms) for Construction Projects" (EB/OL), Ministry of Ecology and Environment Order (No. 9) and supporting documents, Ministry of Ecology and Environment Announcement (No. 38). 